\title{
Colorants: A New Journal Bringing Colour to Life
}

\author{
Anthony Harriman (D)
}

Citation: Harriman, A. Colorants: A New Journal Bringing Colour to Life. Colorants 2022, 1, 1-2. https:// doi.org/10.3390/colorants1010001

Received: 6 September 2021 Accepted: 9 September 2021 Published: 14 September 2021

Publisher's Note: MDPI stays neutral with regard to jurisdictional claims in published maps and institutional affiliations.

Copyright: (C) 2021 by the author. Licensee MDPI, Basel, Switzerland. This article is an open access article distributed under the terms and conditions of the Creative Commons Attribution (CC BY) license (https:// creativecommons.org/licenses/by/ $4.0 /)$.
Molecular Photonics Laboratory, School of Natural and Environmental Sciences, Bedson Building, Newcastle University, Newcastle upon Tyne NE1 7RU, UK; anthony.harriman@newcastle.ac.uk

Colorant: A substance which is used to impart colour to another material!

Most of us have favourite colours that bring us pleasure, transform our moods and attitudes, and change our perceptions. Who can resist a rainbow on a sunny afternoon? Colour is what makes a painting unique and adds dimensionality to flat objects. Nature makes incredible use of colour, better than any artist, and has developed the trick of changing colour on demand. Colour is truly international, crossing the boundaries of languages, and features in cosmology by way of the red planet. Apart from refraction and reflection, colour is generated by the inclusion of some type of colorant, which could be molecular, oligomeric, particulate, or macroscopic. Such colorants have been prominent in human development. They have been considered precious commodities since the earliest days and, in many cases, have brought fortunes to merchants and communities. Some colorants, such as indigo, have revolutionized clothing, being instantly recognizable, and are still being researched today [1]. There are important differences between dyes and pigments [2], but the term "colorant" covers all such materials. The chemical composition of a colorant is a key tool in the battle against forgeries [3], while the in situ analysis of ancient colorants has fuelled the development of sophisticated spectroscopic tools [4]. The stability of colorants can vary dramatically, covering the time window from centuries to microseconds, and is an important research field in its own right.

The journal Colorants (ISSN: 2079-6447) [5] is a new, open access journal marketed by MDPI, which publishes full research papers, reviews, and communications. The mission is to publish high-quality research covering all aspects of the chemistry and physics associated with natural and synthetic colorants. Both experimental and theoretical studies devoted to synthesis, analysis, composition, and dispersion characteristics are appropriate for inclusion in the journal. Manuscripts dealing facets of colorant stability, reactivity, and transformation fall well within the scope of the journal. Aggregation is known to be an important aspect in controlling the properties of synthetic colorants and spectroscopic or kinetic studies aimed at monitoring the accretion of colorant entities will be considered. The application of new tools for the analysis of old colorants will be a feature of the journal and we hope to have regular submissions on this hugely popular subject. Submissions covering both basic and applied research are welcome. In addition, submissions devoted to the history, economics, and social impact of colorants are strongly encouraged.

Special Issues that highlight emerging areas of research will appear at frequent intervals, and suggestions for new topics should be directed to the Editor-in-Chief. All manuscripts will be thoroughly peer-reviewed in a timely fashion, with a first decision within 15 days and acceptance to publication within 3 days (median values for MDPI journals in the first half of 2021). The publisher has appointed a strong Editorial Board, comprising outstanding researchers active in many disparate areas of colorant research, to advise and complement the Editorial Team. Colorants aims to become the journal for all research in the science of colour.

Conflicts of Interest: The author declares no conflict of interest. 


\section{References}

1. Seixas de Melo, J.S.; Burrows, H.D.; Serpa, C.; Arnaut, L.G. The Triplet State of Indigo. Angew. Chem. Int. Ed. 2007, 46, 2094-2096. [CrossRef] [PubMed]

2. Towns, A. Colorants: General Survey. Phys. Sci. Rev. 2019, 4, 1-17. [CrossRef]

3. Nielsen, S.E.; Scaffidi, J.P.; Yezierski, E.J. Detecting Art Forgeries: A Problem-Based Raman Spectroscopy Lab. J. Chem. Educ. 2014, 91, 446-450. [CrossRef]

4. Beeby, A.; Gameson, R.; Nicholson, C. New Light on Old Illuminations. Arch. Rec. 2018, 39, 244-256. [CrossRef]

5. Colorants Home Page. Available online: https://www.mdpi.com/journal/colorants (accessed on 6 September 2021).

\section{Short Biography of Author}

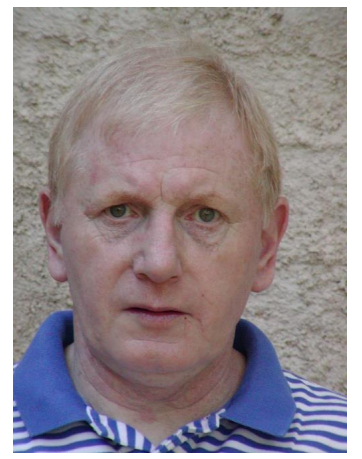

Anthony Harriman began his career working at the Industrial Research Laboratory of Mander Paints Ltd. in Wolverhampton, where he developed an interest in the photostability of pigments and in their ability to photosensitize oxidative damage to the resins. This was followed by a Ph.D. in the photochemical degradation of polymers, before moving to the Royal Institution of Great Britain in London to begin research on artificial photosynthesis. This latter work, carried out in collaboration with Lord George Porter, centred on the use of porphyrins and phthalocyanines as photosensitizers. In 1988, he moved to the USA as Director of the Center for Fast Kinetics Research at the University of Texas at Austin. There, the photophysical properties of many disparate types of pyrrole-based chromophores were measured on very different timescales. He returned to Europe in 1994 and spent a short time at ECPM-Strasbourg, where he collaborated mostly with Raymond Ziessel in the study of the photophysics of transition metal complexes. At the end of 1998, he moved to Newcastle University and soon began working with boron dipyrromethene fluorophores. These synthetic dyes have been used to examine many aspects of light-induced energy and electron transfer, and form the basis for applications where changes in emission can provide key structural or environmental information. Recent work has seen the development of numerous intricate molecular architectures housing BODIPY or related chromophores. A separate study explored the photophysics of other boron(III) chelates. Professor Harriman has received many awards for his research, including the RSC Corday-Morgan medal, the Grammatikakis-Neumann Prize and the RSC Chemical Dynamics Award. He has given many plenary lectures at major conferences and authored more than 400 research articles. 